\title{
Ideologia, \\ política, cultura: passo a passo
}

\author{
Décio Pignatari
}

Certas datas emitem energia e descargas significantes, como baterias históricas; são data, dados, no sentido da informática, continuamente processados para a geração de significados. 1895: suicida-se Raul Pompéia, misógino, simbolista da prosa de ficção, fiorianista feroz e fracassado, positivista pelo avesso: o caminho está aberto para os poetas parnasianos positivistas do sistema, com Olavo Bilac à frente; 1896: inicia-se a campanha de Canudos, sob o primeiro governo civil da República, o de Prudente de Morais: explode o gênio do positivista Euclides da Cunha, acusando uma contradição republicana enorme: Canudos foi um genocídio. Não significaria isto que há várias raças e povos vivendo, e mal vivendo, sob uma rubrica falsamente homogeneizadora, Estados Unidos do Brasil? Por que as secessões não vingaram até hoje - e sim as sucessões de elites e castas? Freud publica A interpretação dos sonhos em 1900; dois anos depois, é a vez da interpretação dos pesadelos brasileiros: sai Os sertões, de Euclides da Cunha. O Brasil entra no século XX mediante um trauma de parto, a fórceps: teriam os seus miolos sido afetados?

De que revoluções falamos? Temos as político-ideológicas, as sociais, as tecnológicas, as industriais. No Brasil, nunca distinguimos umas das outras, mas elas se dão em caminhada paralela, passo a passo, por atrasados ou adiantados que estes estejam. 1870: o poeta maranhense Joaquim de Sousândrade, republicano ferrenho e feroz, depois de
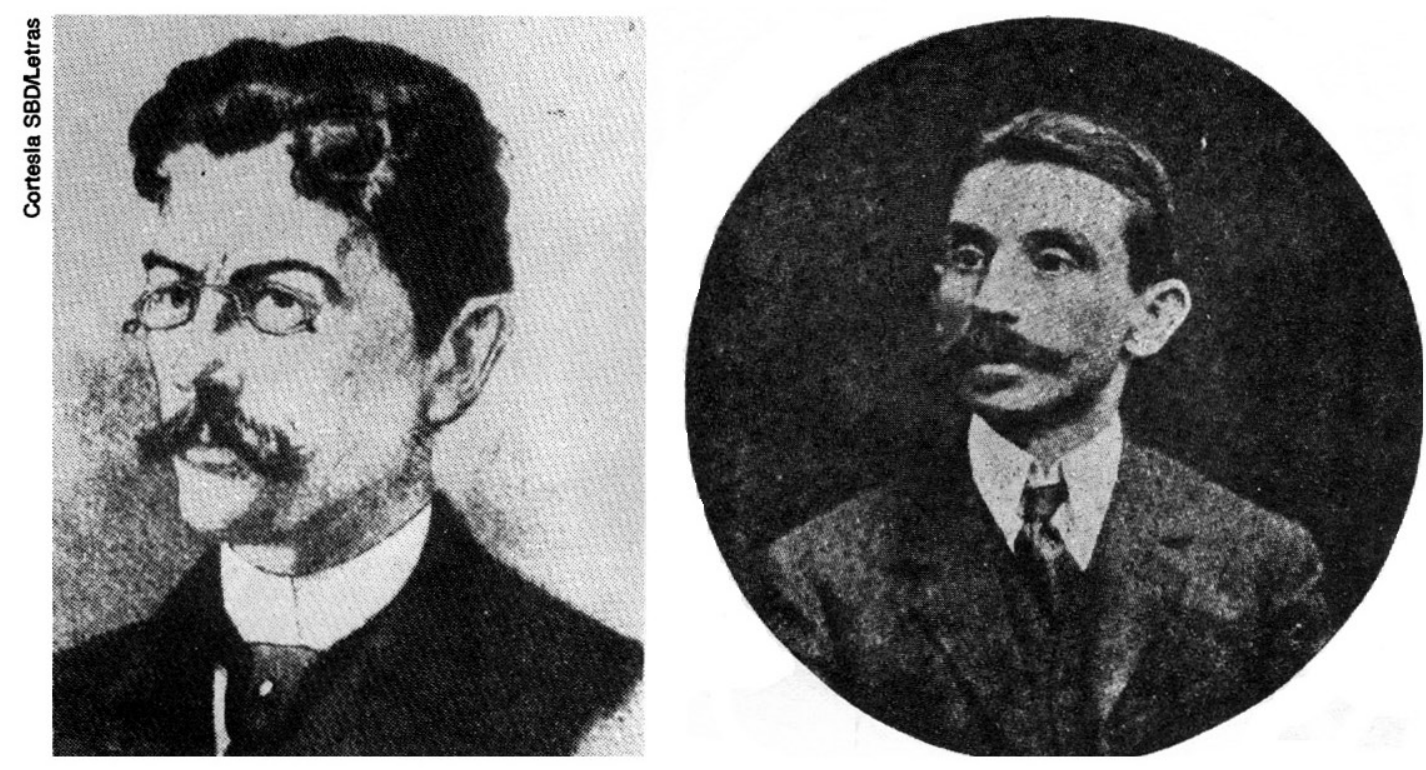

DÉCIO PIGNATARI é professor da FAU-USP, poeta, tradutor e ensaísta. É autor de, entre outros livros, Poesia pois é poesia (Editora Brasiliense) e $A$ signagem da televisāo (Editora Brasiliense).

Da esquerda para a direita: Raul Pompéia, Euclides da Cunha e Souzândrade
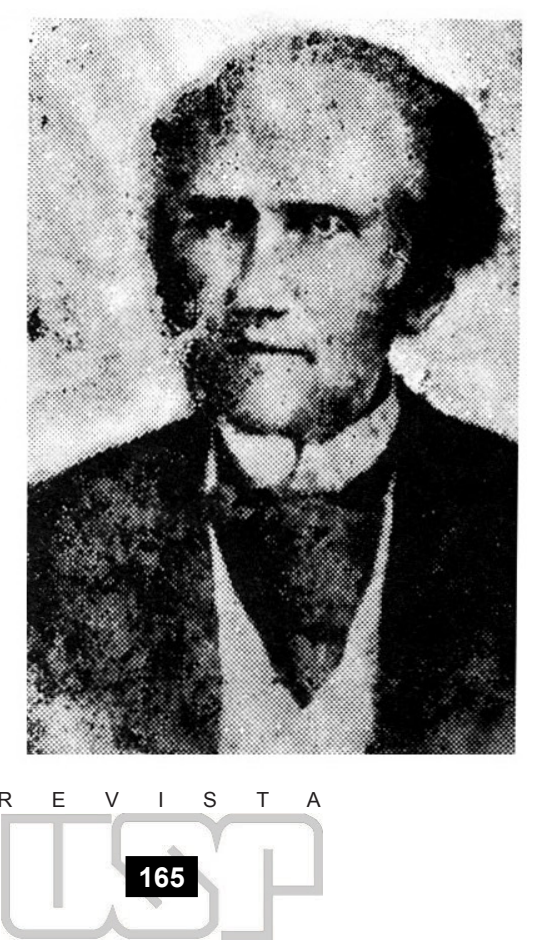
escravos e os imigrantes que os vieram substituir. Não são poucos os que incriminam a ausência de "brasileirismo" em Machado de Assis, tentando opor-lhe a brasilidade do mulato Lima Barreto, nem por isso menos oprimido. Foram negros três dos melhores escritores brasileiros do século passado: Machado, Cruz e Souza e Kilkerry (este, em verdade, fazendo a transição para o século atual). Os três são internacionalistas. Como poderia ser diferente? Como pretender que fossem nacionalistas aqueles cujos ascendentes foram seqüestrados, escravizados e torturados pelos senhores luso-brasileiros? A situação deles, à época, era semelhante à dos índios atuais - que são raças e nações dominadas pelos mesmos senhores, classe dominante ora acrescida dos descendentes dos escravos e dos imigrantes "assimilados". E como pretender que os imigrantes não fossem internacionalistas, vindo, como vinham - além do mais - trazendo um repertório superior na bagagem do exílio voluntário, pertencentes à terceira geração da revolução industrial, embora oriundos do campo, na maior parte?

Esmagada Canudos, a primeira República ingressa na belle époque. Mas o mundo civilizado europeu parece dar mostras de enfado em relação a essa bela época - tentando esconder suas contradições - e parte para a barbárie: é a Primeira Guerra Mundial, que terá imediata influência na cultura brasileira. $\mathrm{O}$ cinema já está produzindo obras-primas, como $O$ nascimento de uma nação, de Griffith, de 1917; os arranha-céus de Nova York espantam Bilac, que faz mais um soneto; surge Dadá, após a revolução cubista, que encontra em Apollinaire o seu primeiro defensor teórico - mas o grande poeta morrerá apenas terminado o conflito; Debussy, Schoenberg e Stravinsky já detonaram os arraiais da música tonal; Proust está concluindo sua busca do tempo perdido. No Brasil, a exposição de telas modernas de Anita Malfatti provoca a ira de Monteiro Lobato. Mas, com a alta do café nos mercados internacionais, as condições estão criadas para a deflagração da Semana de Arte Moderna. A revolução bolchevique e a fundação do Partido Comunista Brasileiro não terão grande influência no evento: sua influência só se fará sentir nos anos 30, após a revolução varguista, e após o crack da Bolsa de Nova York: estes eventos conjugados determinarão a morte da fase experimental dos modernistas e o surgimento do romance regionalista do nordeste - embora Oswald de Andrade continue tentando inovar, mas na área do teatro.

$\mathrm{O}$ aventureirismo especulativo ianque dava nova força aos ditadores, de direita e esquerda: Mussolini, Stalin, Salazar, Hitler, Franco. E Vargas: "Vamos fazer a revolução antes que o povo a faça", 1930. É o fim do modernismo, é o fim da cidade, é o fim da industrialização. Voltam a prevalecer o campo e o latifúndio dos tempos do Império. Getúlio Vargas consegue cooptar o operariado - com a ajuda organizacional de Roberto Simonsen, o Mauá do sistema corporativista brasileiro, e com a inestimável colaboração do PCSB, Partido Comunista Stalinista Brasileiro. O efeito é imediato. Até o catolicão quase-latifundiário Oswald de Andrade (com o empurrão decisivo de Pagu, sua musa hippie-anarco-comunista) se converte ao comunismo, em menos de um ano! Resumindo: a guerra de 14 criou o nosso modernismo, o crack da Bolsa de NY acabou com ele e

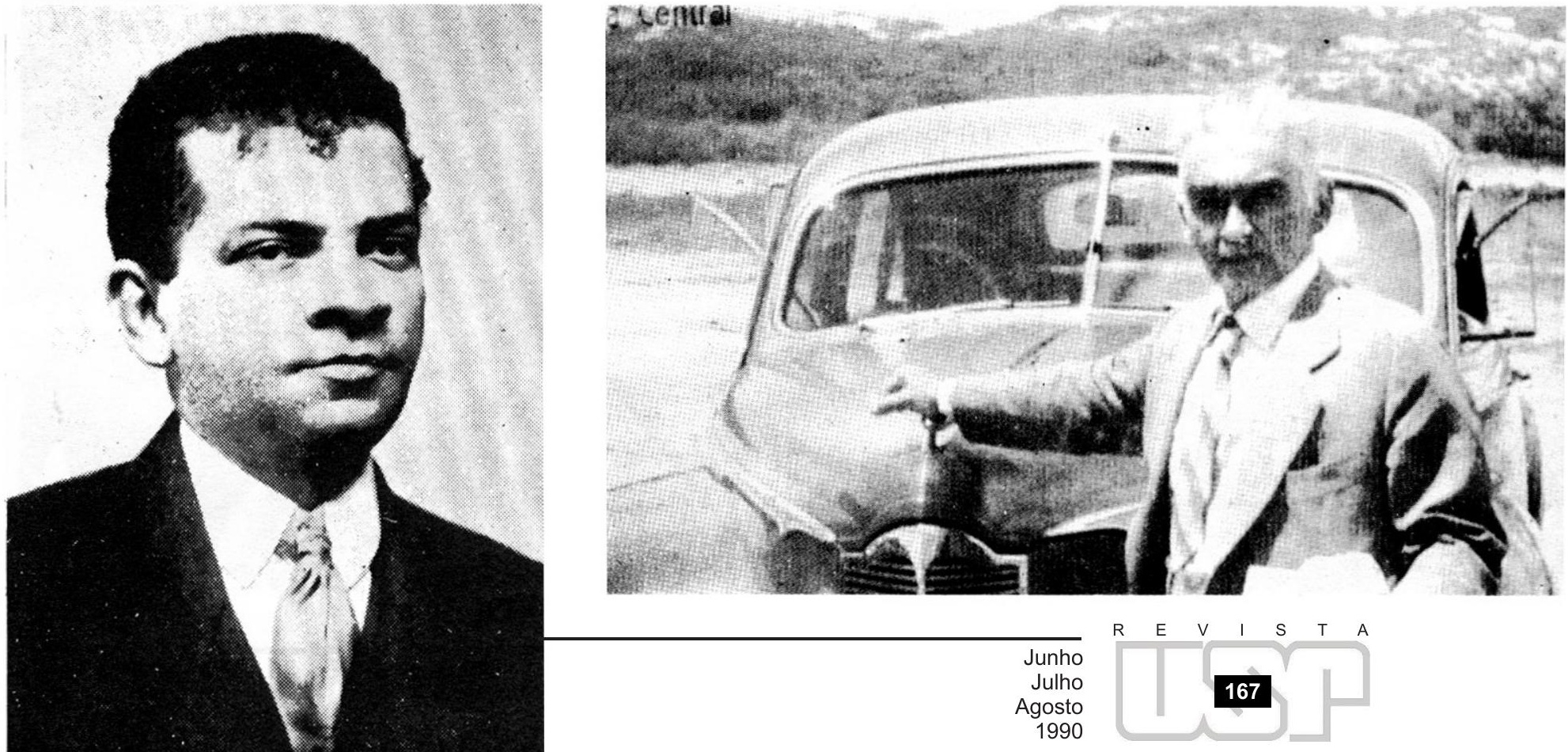


